\title{
Lubricated sliding wear behaviour of aluminium alloy composites
}

\author{
J.C.Walker*, W.M.Rainforth, H.Jones \\ Department of Engineering Materials, University of Sheffield, UK \\ j.walker@sheffield.ac.uk
}

\begin{abstract}
Interest in aluminium alloy composites as wear resistant materials continues to grow. However, the use of the popular Al-alloy-SiC composite can be limited by the abrasive nature of the $\mathrm{SiC}$, leading to increased counterface wear rates. This study reports new Al-alloy composites that offer high wear resistance, to a level similar to Al-alloy-SiC. Aluminium alloy $(2124,5056)$ matrix composites reinforced by nominally 15 vol.\% of $\mathrm{Cr}_{3} \mathrm{Si}, \mathrm{MoSi}_{2}$, $\mathrm{Ni}_{3} \mathrm{Al}$ and $\mathrm{SiC}$ particles were prepared by a powder metallurgy route. The aluminium alloy matrix was produced by gas atomisation, the $\mathrm{Cr}_{3} \mathrm{Si}, \mathrm{MoSi}_{2}$ and $\mathrm{Ni}_{3} \mathrm{Al}$ were prepared by self propagating high temperature synthesis (SHS), while the $\mathrm{SiC}$ was from a standard commercial supply. Following blending, the particulates were consolidated by extrusion, producing a homogenous distribution of the reinforcement in the matrix. Wear testing was undertaken using a pin-on-ring configuration against an M2 steel counterface, with a commercial synthetic oil lubricant, at $0.93 \mathrm{~m} / \mathrm{s}$ and a normal load of $630 \mathrm{~N}$, corresponding to initial Hertzian contact pressures of $\sim 750-890 \mathrm{MPa}$ (the exact value depending on the material properties). Specific wear rates at sliding distances exceeding $400 \mathrm{~km}$ were in the range $12.7-$ $4.5 \times 10^{-10} \mathrm{~mm}^{3} / \mathrm{Nm}$. The monolithic alloys gave the highest specific wear rates, while the $\mathrm{MoSi}_{2}$ and $\mathrm{Cr}_{3} \mathrm{Si}$ reinforced alloys exhibited the lowest. The worn surface has been analysed in detail using Focused Ion Beam (FIB) microscopy to determine the sub-surface structural evolution and by tomographic reconstruction of tilted SEM images, to determine the local
\end{abstract}


worn surface topography. Consequently, the wear mechanisms as a function of alloy composition and reinforcement type are discussed.

Keywords: Lubricated sliding, Aluminium composites, Focused ion beam.

\section{Introduction}

Interest in aluminium based metal matrix composites (MMCs) continues to grow, especially from the transport industries, where component weight reduction is a key objective $[1,2]$. Since the 1980s there had been extensive investigation of aluminium MMCs reinforced with hard ceramic phases, such as $\mathrm{Al}_{2} \mathrm{O}_{3}$ or $\mathrm{SiC}$, in an effort to understand and improve the tribological properties of aluminium [3-15]. Whilst to an extent this has been successful, some authors $[3,5,8,11,16]$ have noted that a critical load exists during dry sliding, above which a ceramic based composite offers little improvement in wear resistance compared to an un-reinforced sample. Indeed, others $[5,8-10,17]$ have found that hard ceramics can actually increase the wear rate of the mating counterface, due to their abrasive action, and thus reduce the overall wear resistance of the tribo-system.

Intermetallics such as $\mathrm{NiAl}$ and $\mathrm{Ni}_{3} \mathrm{Al}$ have been shown to improve the wear resistance of aluminium alloys to a level similar to that of a $\mathrm{SiC}$ reinforced composite, whilst at the same time reducing counterface wear rates [17-21]. Whilst most of the available literature on wear of intermetallic reinforced aluminium MMCs pertains to dry sliding conditions, for sliding contacts where high friction and wear are undesirable the use of a lubricant becomes necessary.

This study investigates the lubricated sliding response of two aluminium alloys, 2124 and 5056 produced through a powder metallurgy/extrusion process [17,18,22]. Their behaviour is compared to similar alloys reinforced with a number of particulate 
intermetallics; $\mathrm{Ni}_{3} \mathrm{Al}, \mathrm{Cr}_{3} \mathrm{Si}$ and $\mathrm{MoSi}_{2}$, as well as with a more conventional $\mathrm{SiC}$ ceramic, produced through the same process. $\mathrm{Ni}_{3} \mathrm{Al}$ has already shown good tribological behaviour as a reinforcement under dry sliding conditions [17,18,21], however $\mathrm{Cr}_{3} \mathrm{Si}$ and $\mathrm{MoSi}_{2}$ are novel reinforcements, chosen for their high elastic modulus, but lower hardness compared to SiC. Previous studies [22] have shown that a $15 \mathrm{vol} . \%$ reinforcement of $\mathrm{Cr}_{3} \mathrm{Si}$ and $\mathrm{MoSi}_{2}$ in a 2124 matrix provided composites with similar yield strengths to that of $2124+15 \mathrm{vol} \% \mathrm{SiC}$, but with improved ductility.

The wear mechanisms involved are discussed as a function of lubrication, alloy and reinforcement compositions. Relative wear resistance of samples is compared using specific wear rates calculated as a function of volume loss, whilst results of extensive scanning electron surface microscopy, coupled with 3D tomographic reconstruction and the investigation of selected sub-surface regions using focused ion beam techniques are also presented.

\section{Experimental Procedure}

Consolidated 2124 and 5056 composites reinforced with $\mathrm{Cr}_{3} \mathrm{Si}, \mathrm{MoSi}_{2}, \mathrm{Ni}_{3} \mathrm{Al}$ and $\mathrm{SiC}$ particulates were produced through a powder metallurgy/extrusion process, detailed elsewhere $[17,18,22]$, but summarised as follows. Aluminium alloy powders were produced by inert gas (argon) atomisation, with a mean particle size, $\mathrm{d}_{50}$ of $28 \mu \mathrm{m}$ and supplied by Alpoco, Sutton Coldfield, UK; compositions are detailed in Table 1. $\mathrm{Cr}_{3} \mathrm{Si}, \mathrm{MoSi}_{2}, \mathrm{Ni}_{3} \mathrm{Al}$ intermetallic powders, supplied by INASMET, San Sebastian, Spain, were produced by selfpropagating high temperature synthesis (SHS), followed by mechanical milling and grading to obtain particles sizes $<10 \mu \mathrm{m}$. SiC powder with a mean particle size of $5 \mu \mathrm{m}$ was obtained from a standard commercial supply. Reinforcement properties are detailed in Table 2. 
Particulate $\mathrm{Cr}_{3} \mathrm{Si}, \mathrm{MoSi}_{2}$ were individually blended with 2124 and 5056 alloy powders to give a nominal $15 \mathrm{vol} . \%$ reinforcement. $\mathrm{SiC}$ and $\mathrm{Ni}_{3} \mathrm{Al}$ were also individually blended with 2124 and 5056 alloy powders, respectively, to give the same volume fraction reinforcement. The mixed powders were cold compacted at 300MPa for 3 minutes, by Creuzet, Marmande, France, prior to final consolidation by hot extrusion at $400-450^{\circ} \mathrm{C}$, with extrusion ratios of 77:1 for intermetallic composites and 30:1 for un-reinforced and $\mathrm{SiC}$ reinforced composites. Extrusion of both 2124 and 5056 un-reinforced alloys was also undertaken in a similar manner, for comparative purposes. $2124+\mathrm{SiC}$ was heat treated to the $\mathrm{T} 351$ condition after extrusion, for optimal hardness, while the other 2124 composites were simply water quenched and naturally aged. Vickers microhardness (200g-15s) and optical micrographs of each extruded polished transverse section were made.

Lubricated sliding wear tests of all specimens were conducted using a Cameron-Plint TE-53 multipurpose friction and wear tester, with a pin-on-ring geometry, according to the procedure outlined in ASTM standard G77. A commercial synthetic motor oil, Mobil 1 Motorsport (SAE 15W-50) was used to give optimal lubrication, with a viscosity of $1.0 \times 10^{-4}$ $\mathrm{kg} \mathrm{m}^{-1} \mathrm{~s}^{-1}$ at $40^{\circ} \mathrm{C}$. Pin specimens were prepared by sectioning across the transverse direction of the extruded material at $12.8 \mathrm{~mm}$ intervals and then grinding/polishing to a $1 \mu \mathrm{m}$ polished finish. The counterface was a crowned M2 tool steel ring, of $60 \mathrm{~mm}$ principle radius with a crown radius of $100 \mathrm{~mm}$, hardened to $705 \mathrm{H}_{\mathrm{V}}$ and also polished to a $1 \mu \mathrm{m}$ finish, giving $\mathrm{R}_{\mathrm{a}}$ values between $0.1-0.2 \mu \mathrm{m}$. A second counterface of exactly the same dimensions, but higher hardness of $882 \mathrm{H}_{\mathrm{v}}$ was used to test the un-reinforced 5056 alloy. This was necessary due to cracking and failure of the original counterface.

Testing was carried out at a constant sliding velocity of $0.94 \mathrm{~ms}^{-1}(300 \mathrm{rpm})$ and a normal load of $630 \mathrm{~N}$. This corresponded to the initial Hertzian contact pressures for point contact, determined for composites by a rule of mixtures [23], shown in Table 3 , and in the 
range $\sim 750-890 \mathrm{MPa}$ for the composite materials whilst slightly lower for the un-reinforced alloys. These values exceeded the Tresca criterion for initial sub-surface yielding, but were low enough to ensure that significant plastic deformation from the bulk to the surface did not take place. Friction coefficient was measured by means of a load transducer, recording the lateral force on the shaft holding the pin specimen.

Tests for all materials were run for extended periods to assess the wear resistance over large sliding distances. Frequent interruptions were made to remove, clean (teepol/acetone) and weigh specimens to $\pm 0.1 \mathrm{mg}$; however, as mass loss was minimal, measurement of the final wear scar dimensions became the only effective way to measure volume losses. Sample lengths across the short axis of the elliptical wear scar were taken at $0.5 \mathrm{~mm}$ intervals along the length of the scar. The volume of each $0.5 \mathrm{~mm}$ sample interval, $V_{i}$ was calculated using equation (1):

$$
V_{i}=0.125\left[D^{2} \arcsin \left(\frac{d}{D}\right)-d\left(D^{2}-d^{2}\right)^{0.5}\right]
$$

where $D$ is the reduced diameter of the counterface (taking account of the crown) and $d$ is the sample width measured from the wear scar. The total volume loss for the scar is taken as the sum of the individual sample intervals. Mass loss (and subsequently volume loss measurements from density values) were later made to an accuracy of $\pm 0.001 \mathrm{mg}$ for 2124 and 5056 alloys, and showed good correlation with volume loss data from scar dimensions. Tests were recommenced after specimens had been replaced in exactly the same position, and any necessary top up of the lubricant made. Comparison of relative wear rates was made by calculation of the specific wear rate (otherwise known as the dimensional or Lancaster wear coefficient, $K^{\prime}$ [24]). 
Detailed analysis of the worn surface was carried out using scanning electron microscopy (SEM, Jeol 840, 6400, 6500F) operating in the range 7-20kV. Backscattered electron images $(20 \mathrm{kV})$ were used to assess the volume fraction of reinforcement present at the worn surface, through point counting. Energy dispersive X-ray (EDX) analysis was performed on selected areas using an Oxford Exl system on Jeol 6400 and a Rontec system on Jeol 840. Secondary electron images were also used to obtain stereo pairs at $16^{\circ}$ tilt to each other. Mex software, from Alicona, allowed tomographic reconstruction of surface topography from these images, providing depth profiles.

Focused ion beam (FIB, Jeol 6500F Fabrika) microscopy was used to determine the sub-surface structure of selected areas of the worn surface. A beam of gallium ions operating at $30 \mathrm{kV}$, and $1.5 \mu \mathrm{A}$ beam current, was used to mill trenches approximately $10 \mu \mathrm{m}$ wide and $4 \mu \mathrm{m}$ deep. Subsurface features were then imaged using the FIB, at a probe current of 5090pA, which also provides information from ion channelling contrast about grain orientations.

\section{Results}

\subsection{Starting Microstructure}

The microstructure of the as-extruded specimens was made up of a relatively even distribution of reinforcement throughout the matrix, as shown for $5056+\mathrm{MoSi}_{2}$ in Figure 1 , with a minimal amount of porosity $(<2 \%)$. The shape of the silicide particulate reinforcements was relatively equiaxed, whereas higher aspect ratios were seen for both the angular $\mathrm{SiC}$ particles and the more rounded $\mathrm{Ni}_{3} \mathrm{Al}$ particles, which had occasionally led to the incomplete flow of 5056 matrix around the $\mathrm{Ni}_{3} \mathrm{Al}$ particles. Vickers microhardness values, represented in Figure 2, were generally higher for the naturally aged 2124 alloy and 
composites, compared to 5056 alloy and composites, with artificially aged (T351) $2124+\mathrm{SiC}$ showing the highest hardness.

\subsection{Specific Wear Rate}

Figure 3 and Table 4 give the specific wear rate for all samples after lubricated sliding, with values ranging from approximately $8 \times 10^{-11}$ to $1 \times 10^{-9} \mathrm{~mm}^{3} / \mathrm{Nm}$. The un-reinforced 2124 and 5056 alloys showed the highest wear rates at $5 \times 10^{-10}$ and $11 \times 10^{-10} \mathrm{~mm}^{3}(\mathrm{Nm})^{-1}$, respectively. The change of scar geometry with sliding distance for 5056 alloy was recorded in more detail and revealed that after an initial high volume loss $\left(\sim 0.4 \mathrm{~mm}^{3}\right)$, additional losses for the remainder of the test were negligible, thus reducing the specific wear rate with sliding distance.

In accordance with previous studies $[9,10,15], \mathrm{SiC}$ reinforcement significantly improved the lubricated sliding wear resistance of the aluminium alloy, to approximately $2 \times 10^{-10} \mathrm{~mm}^{3} / \mathrm{Nm}$. The same matrix reinforced with silicide intermetallics $\mathrm{Cr}_{3} \mathrm{Si}$ and $\mathrm{MoSi}_{2}$ showed a similar wear resistance $\sim 1 \times 10^{-10} \mathrm{~mm}^{3} / \mathrm{Nm}$, and even lower with a 5056 matrix, in particular $5056+\mathrm{MoSi}_{2}$, which exhibited a wear rate of around $8 \times 10^{-11} \mathrm{~mm}^{3} / \mathrm{Nm}$ after sliding for $467 \mathrm{~km}$. 5056 reinforced with $\mathrm{Ni}_{3} \mathrm{Al}$ particles wore at a similar rate to 2124 reinforced with SiC.

\subsection{Friction Coefficients}

Average friction coefficients for all tests were within the range 0.01-0.11, as detailed in Table 4, the higher values all being for the silicide reinforced composites. Figure 4 shows the typical friction behaviour observed during the tests, where a large friction peak was associated with the initial rotation of the counterface from stationary. This high value of $\mu$ was not sustained for a significant sliding distance, and reduced to a lower, steady value for 
the duration of the test interval. Although average friction values between tests intervals varied a little, this pattern of behaviour was universal for all tests, except for perhaps $2124+$ $\mathrm{SiC}$ and the un-reinforced alloys, where fluctuations were occasionally seen for distances of 10-20km, before levelling out again.

\subsection{Worn surface observations}

An elliptical wear scar characterised the worn surface of each pin to the naked eye, whilst optical microscopy revealed a distinctive leading edge that was the primary contact point of the counterface. The opposite edge was less apparent and often contained pits and short, but deep grooves associated with the ejection of material from the contact region. Profilometry of a number of scars indicated that the latter edge of the scar was sometimes raised from its initial surface plane, suggested some plastic flow of material at the constricted exit.

Secondary electron images of 2124 and 5056 un-reinforced alloys, in Figures 5a) and 6a) respectively, showed a surface containing voids and loose particles, some of which appear to be embedded in the matrix. The 5056 alloy also exhibited smooth, broad wear tracks, of the order $\sim 10 \mu \mathrm{m}$ wide, along with deeper grooves, $\sim 1-2 \mu \mathrm{m}$ wide. Severe ploughing was found on the surface of the $2124+\mathrm{SiC}$, as shown in Figure 5b), as well as detachment of $\mathrm{SiC}$ particles at the particle/matrix interface. Wear grooves were seen to pass through both matrix and reinforcement in $5056+\mathrm{Ni}_{3} \mathrm{Al}$, as shown in Figure 6b). However, more significantly, within the central region of this scar, cracks ran through the matrix within the vicinity of large craters.

The composites reinforced with $\mathrm{Cr}_{3} \mathrm{Si}$ and $\mathrm{MoSi}_{2}$ exhibited extensive fracture of the silicides, Figures 5c)-d) and 6c)-d). Again, directional ploughing was observed, through both reinforcement and matrix. Importantly, there appeared to be an increase in reinforcement particle volume fraction at the worn surface, which was subsequently confirmed by point 
counting of backscattered electron images, namely from $15 \mathrm{vol} . \%$ to $27 \%$ and $28 \%$ for $2124+$ $\mathrm{Cr}_{3} \mathrm{Si}$ and $\mathrm{MoSi}_{2}$ and $38 \%$ and $34 \%$ for $5056+\mathrm{Cr}_{3} \mathrm{Si}$ and $\mathrm{MoSi}_{2}$, respectively.

Backscattered electron images of all samples revealed particles other than reinforcements, of the order $1 \mu \mathrm{m}$ and less, lying embedded in the matrix, as in the case of 2124, Figure 7a). Stretches of these particles were seen parallel to the sliding direction, particularly in the case of $2124+\mathrm{SiC}$, around proud $\mathrm{SiC}$ particles. EDX analysis of both of these regions confirmed the presence of $\mathrm{Fe}$ and other elements associated with particle transfer from the counterface.

\subsection{Tomographic Reconstruction}

Tomographic reconstruction of tilted SEM stereo pairs such as those in Figures 8-12 give information about specific height distributions over the worn surface. The overall height

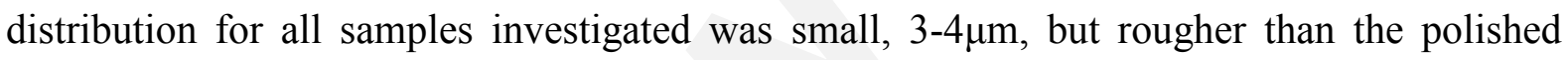
starting surfaces. A greater height difference was observed with $5056+\mathrm{Ni}_{3} \mathrm{Al}$, Figure 10 , where although the wear surface was within the same roughness scale, craters extended as deep as $12 \mu \mathrm{m}$. Interestingly, some Fe-rich particles were found implanted into the surface of

the 5056 alloy, Figure 8 . However, as shown by the corresponding texture depth image, the height difference between these particles and the surrounding matrix was negligible, although deeps pits were often seen immediately behind. Figure 12 confirmed the severity of abrasion clearly visible at the worn surface of $2124+$ SiC. Surface height changes were abrupt, perpendicular to the sliding direction, as the peaks and troughs of multiple wear tracks were traversed, in contrast to other samples where surface gradients were much shallower. 


\subsection{Focused Ion Beam Microscopy}

The versatility of FIB techniques to analyse site-specific sub-surface behaviour was demonstrated in Figures 13-19. Ion channelling contrast revealed the strain and depth of deformation of aluminium grains. The un-reinforced 5056 alloy, Figure 13 showed heavily deformed grains, strained parallel to the sliding direction, extended to a depth of $1-1.5 \mu \mathrm{m}$ from the surface, with equiaxed grains of the order $2 \mu \mathrm{m}$ at greater distances. A greater amount of plastic deformation appeared below the surface of the lower trench in Figure 13, compared to the upper trench, attributed to the broad wear track. In all samples, subsurface voids were also apparent further away from the region of greatest strain, along with the flow of smaller particles at the grain boundaries towards the sliding direction.

Figure 14 shows a section through a large $(\sim 6 \mu \mathrm{m})$ Fe-rich particle on the surface of the 5056, believed to be from the counterface. It appears that these particles had been pushed along the surface, leaving a distinct wear groove in their wake. Ion beam sectioning through this vicinity revealed numerous interesting features, labelled A-E: A indicates local cracking within the debris; B shows flow of the matrix around the debris particle; C relates to intimate contact between the particle and the matrix; D shows cracking of the matrix and E refers to ploughing of the matrix by a second debris particle. Lines believed to reflect the flow of matrix around the bottom of the particles could just be resolved, although these were somewhat obscured by milling effects (vertical lines, re-sputtered material). Also apparent was the effect of atomic number contrast from the secondary ion emission, where heavier elements appear darker than the matrix, the opposite to backscattered electron contrast $[25,26]$.

The worn surface of the 2124 alloy showed a similar region of heavily deformed grains at approximately $1 \mu \mathrm{m}$ depth, Figure 15 , in trenches milled parallel and perpendicular to the sliding direction. In the trench perpendicular to the sliding direction, the depth of the 
deformed near surface layer was extended at the base of a groove, an effect also seen in Figure 19, where a non-linear wear track passes through the surface of $5056+\mathrm{MoSi}_{2}$. However measurements of plastic deformation from the surface indicated that the region of highest strain is in fact to the sides of the groove and not directly under it, suggesting ductile micro-ploughing instead of a direct load bearing effect.

The strain of certain features such as smaller particles toward the sliding direction would suggest that the total depth of deformation of the sub-surface region extended below the viewable area of these trenches. It does not appear that the strained length of these features reaches a perpendicular geometry at the base of the milled trench.

Figure 16 shows the subsurface microstructure of the $2124+\mathrm{SiC}$ composite, which was distinctly different to others, in that no evidence was found of surface deformation; rather relatively equiaxed grains were seen even at the surface. Indeed it appeared that load transfer has occurred only below the SiC particle standing above the surface, to the left of the image, with heavily deformed grains up to a depth of approximately $2 \mu \mathrm{m}$ below the particle. Angular pits within the surface also suggest that $\mathrm{SiC}$ particles have been removed from these areas.

Milling of the $5056+\mathrm{Ni}_{3} \mathrm{Al}$ specimen, Figure 17, showed that cracks which were clearly visible on the surface of the specimen, also extended below the worn surface, and appeared to be deflected by the presence of a $\mathrm{Ni}_{3} \mathrm{Al}$ particle, to the left of the upper trench. Also apparent in the top trench was the flow of matrix around the $\mathrm{Ni}_{3} \mathrm{Al}$ particle to the left, whilst the total depth of deformation was still in the range $1-1.5 \mu \mathrm{m}$.

Sections through the worn surface of the silicide reinforced alloys, Figure 18, showed fracture and re-embedding of the silicide phases in the matrix at the near surface region, while larger particles away from the worn surface exhibited no visible effect of the wear process. The depth of strain deformation appeared similar to that for the un-reinforced alloys. 
The worn surface of these composites also exhibited what appeared to be surface cracks, parallel to the sliding direction. However, a FIB trench milled perpendicular one of these features, Figure 19, showed them to be non-linear abrasive grooves, with evidence of subsurface plastic deformation and the ability of the reinforcements to deflect the linear propagation of the abrasive particle.

\section{Discussion}

\subsection{Lubricated Sliding Mechanisms}

The presence of transferred Fe on the worn Al-alloy surfaces and the initially high friction coefficients are consistent with boundary lubricated conditions. This was observed particularly in the un-reinforced 2124 and 5056 alloys and $\mathrm{SiC}$ reinforced 2124 alloy, and to a lesser extent in the intermetallic reinforced composites. Initial Hertzian contact stresses were high as a result of non-conformal surfaces, which would preclude any lubrication regime other than boundary. However, as the test proceeded, wear resulted in conformal contact surfaces and a substantial drop in friction coefficient, a pattern consistent with a transition from boundary to mixed lubrication conditions. Nevertheless, the minimal variation in worn surface heights of $3-4 \mu \mathrm{m}$, and specific wear rates of the order $<1 \times 10^{-9} \mathrm{~mm}^{3} / \mathrm{Nm}$ indicated a mild wear regime, in contrast to values of the order $1-10 \times 10^{-4} \mathrm{~mm}^{3} / \mathrm{Nm}$ found for dry sliding of similar alloys $[17,18]$.

\subsection{Effect of Matrix Composition for monoliths}

The overall wear rate for lubricated sliding of the 2124 precipitation hardened alloy at high normal contact loads was lower than for the work hardening 5056 alloy, although the higher hardness of the second test counterface cannot be completely disregarded. The depth of 
deformation for both alloys is similar, which leads to the suggestion that it was the abrasive wear of the softer surface that results in the higher wear rates seen for the 5056 alloy. A similar trend was seen for dry sliding of these alloys against a M2 tool steel counterface, in the load range $42-140 \mathrm{~N}$, by Ghazali et al [27], although, differences evidently exist between the relative wear mechanisms of dry and lubricated sliding.

Transfer of Fe from the counterface was observed for both un-reinforced 2124 and 5056 alloys, as shown by EDX and FIB cross sections, the distribution of which was demonstrated by $3 \mathrm{D}$ surface reconstructions. The abrasive action of these Fe-rich particles is unquestionable, Figure 14, since their presence was characterised by a groove in their wake. The pressure acting on the particles must have been significant, in excess of the flow stress of the Al-alloy, since the majority of the particle was below the worn surface. Moreover, the intimate contact of particle and matrix, with an absence of any significant voids at the interface, further indicates the pressure on the particles. However, it is interesting to note that, although severe plastic deformation was observed in the matrix around these Fe particles, the total depth of severe deformation in other areas of the matrix was not large $(\sim 1.5 \mu \mathrm{m})$. Voids within grains were present below the region of heaviest plastic deformation, indicating that the subsurface stress levels were sufficiently high to cause nucleation, but not high enough for void coalescence to form sub-surface cracks, the exception perhaps being $5056+\mathrm{Ni}_{3} \mathrm{Al}$.

Sections perpendicular to wear grooves in both un-reinforced and reinforced samples showed the extension of the depth of plastic deformation below the groove, Figures 15 and 19. During elasto-hydrodynamic lubrication, where mating surfaces are separated with a significantly thick fluid film, 3-body abrasive particles generated during earlier boundary lubrication conditions can often be larger than the thickness of the film itself, in which case, contact is inevitable [28] and wear proceeds by abrasion. 


\subsection{Effect of reinforcement type}

The incorporation of a $15 \mathrm{vol} . \%$ particulate reinforcement, both ceramic and intermetallic, led to a reduction in the lubricated sliding wear rate of both 2124 and 5056 alloys, of the order 5$10 \times 10^{-10} \mathrm{~mm}^{3} / \mathrm{Nm}$. Although the addition of SiC increased the wear resistance of 2124 alloy, severe abrasion of the surface was observed for this composite, attributed to 3-body abrasive $\mathrm{SiC}$ particles, Figures 5b) and 12. The fracture and removal of $\mathrm{SiC}$ particles at what appeared to be the particle/matrix interface was inferred from the angular geometry of the resulting surface pits. This behaviour has already been reported by Pan et al [9] for peak aged $2124+$ $\mathrm{SiC}$ under similar lubricated conditions. Also observed is the increased amount of Fe transfer from the counterface, particularly around $\mathrm{SiC}$ particles standing proud of the surface. This effect, associated with the abrasive nature of the $\mathrm{SiC}$ is well documented $[3,5,8,11,16]$, but mainly for the case of dry sliding. However, the ability of the $\mathrm{SiC}$ to transfer the applied load to the matrix has also been demonstrated, an effect seen by Alpas and Zhang [3] for SiC particles that stand proud of the surface within aluminium, and also by Perrin and Rainforth [11] for dry sliding of a saffil fibre reinforced Al metal matrix composite. Thus, the present results are consistent with the literature. The $\mathrm{SiC}$ acts as an excellent reinforcement, with the particles acting as load support, transferring stress into the subsurface matrix. However, the abrasive nature of the $\mathrm{SiC}$, particularly from angular liberated particles, leads to 2- and 3body abrasive wear, particularly of the counterface material, as shown by the high levels of Fe transfer.

Intermetallic reinforced composites showed further differences in wear mechanisms, according to the type of reinforcement. $5056+\mathrm{Ni}_{3} \mathrm{Al}$ exhibited a wear rate similar to $2124+$ $\mathrm{SiC}$ however, the more ductile $\mathrm{Ni}_{3} \mathrm{Al}$ did not cause such severe abrasion of the counterface, although small sub-micron particles observed at the worn surface were thought to originate from the counterface. 3D surface reconstructions indicated a much flatter, polished surface, 
with little evidence of direct particle pull-out. Instead, wear appeared to proceed by microploughing and plastic deformation of both particles and matrix, with evidence of matrix flow around reinforcements, Figure 17, an effect also seen by Wang et al [17,18] for dry sliding of similar composites. Further to this was the appearance of deep $(\sim 12 \mu \mathrm{m})$ craters, around a cracked region of the wear scar, with reinforcements appearing to deflect the crack propagation. This behaviour was not seen in the un-reinforced 5056 alloy and therefore could be the result of the initiation of sub-surface cracks at voids between particles with high aspect ratios, where incomplete flow of the matrix around the reinforcement has led to increased porosity. The depth of the craters themselves may give an indication as to the total depth of deformation, not apparent from FIB sectioning of the surfaces.

The highest wear resistance was observed for the silicide reinforced composites, with $\mathrm{MoSi}_{2}$ giving lower wear rates compared to $\mathrm{Cr}_{3} \mathrm{Si}$ in the same matrix. 5056 appeared to be a better composite matrix than 2124 , a reversal of what was found for lubricated sliding of the un-reinforced alloys. Although abrasion through micro-ploughing, coupled with the appearance of sub-micron Fe particles at these worn surfaces appeared to be similar in magnitude to that of $5056+\mathrm{Ni}_{3} \mathrm{Al}$, there was evidence that the silicide reinforcements could resist ploughing of abrasive particles, deflecting the propagation of wear grooves within the matrix, Figure 19. Application of high contact stresses caused localised fracture of the silicide phase at the near surface region, Figures 5 and 6; c) and d). 3D reconstruction suggested that the fracture was both through the particles themselves, but also at the particle/matrix interface, given the size of some of the resulting voids. The subsequent redistribution of liberated silicide back into the matrix led to a higher volume fraction reinforcement at the surface, and hence a harder contact area. Indeed, many authors [6,12-14,29] have observed that increasing the volume fraction of a harder reinforcement phase often leads to a direct improvement in wear resistance. The better wear resistance of a 5056 silicide reinforced 
matrix compared to a similar 2124 composite could be attributed to the $\sim 20 \%$ increase in surface reinforcement volume fraction, compared to only a $\sim 10 \%$ increase for the corresponding 2124 silicide reinforced matrix. This significant difference was a result of the difference in hardness of the two alloys and suggests that a more ductile matrix with a harder reinforcement, which initially fractures but then re-implants itself into the surface, is an optimal combination for lubricated wear resistance. The benefit of using a reinforcement that does not plastically deform, but does not have such high hardness so as to cause significant damage to the counterface is also apparent.

\subsection{Summary}

The predominant wear mechanism during lubricated sliding of 2124 and 5056 aluminium alloys was mild wear by abrasion. 2- and 3-body abrasives, particularly from the counterface, plastically deformed the surface by micro-ploughing and indentation.

The introduction of a harder reinforcing second phase to the matrix resulted in an improvement of wear resistance for both alloys. However, use of the hard ceramic $\mathrm{SiC}$ as a reinforcement caused severe abrasion of both contacting surfaces. The use of intermetallics as reinforcement materials allowed similar improved wear rates to that of $2124+\mathrm{SiC}$ to be obtained, but with less apparent damage and transfer of material from the counterface. This is believed to be a direct result of their lower hardness.

In the case of the silicide reinforced composites, the best wear resistance, particularly for $5056+\mathrm{MoSi}_{2}$, was achieved by the ability of the composites to optimise the near surface layer. Silicide particles exceeded their fracture toughness under the applied contact stress and liberated small particles as debris. Re-implantation of these debris particles, facilitated by the lubricant, into a ductile matrix, increased the local volume fraction reinforcement and hence overall surface hardness. 


\section{Acknowledgements}

Grateful thanks is given to EPSRC (UK) for funding the studentship for this project, and also to CENIM, Madrid, Spain, for use of their scanning electron microscope facilities during July to September 2003.

\section{References}

[1] G. Curran, C. Baker, MMCs: The Future \& Metal Matrix Composites VI, Materials World 6 (1998) 20-23.

[2] K. Shibata, H. Ushio, Tribological application of MMC for reducing engine weight, Trib. Int'l. 27 (1994) 39-41.

[3] A.T. Alpas, J. Zhang, Effect of microstructure and counterface material on the sliding wear resistance of particulate reinforced aluminium matrix composites, Metall. Trans. 25A (1994) 969-983.

[4] A. Sato, R. Mehrabian, Aluminium matrix composites: Fabrication and properties, Metall. Trans. 7B (1976) 443-451.

[5] R. Chen, A. Iwabuchi, T. Shimizu, H. Mifune, H.S. Shin, The sliding wear resistance behaviour of $\mathrm{NiAl}$ and $\mathrm{SiC}$ particles reinforced aluminum alloy matrix composites, Wear 213 (1997) 175-184.

[6] F.M. Hosking, F. Folgar Portillo, R. Wunderlin, R. Merhabian, Composites of aluminium alloys: Fabrication and wear behaviour, J. Mater. Sci. 17 (1982) 477-498.

[7] J. Jiang, A. Ma, H. Lui, R. Tan, The wear properties of an alumina-aluminosilicate fibre hybrid reinforced Al-Si alloy in a lubricated condition, Wear 171 (1994) 163168. 
[8] A.J. Leonard, C. Perrin, W.M. Rainforth, Microstructural changes induced by dry sliding wear of a A357/SiC metal matrix composite, Mater. Sci. Technol. 13 (1997) 41-48.

[9] Y.M. Pan, M.E. Fine, H.S. Cheng, Ageing effects on the wear behaviour of P/M aluminium alloy SiC particulate composites, Scr. Metall. 24 (1990) 1341-1345.

[10] Y.M. Pan, M.E. Fine, H.S. Cheng, Sliding wear of an Al alloy SiC whisker composite, Trib. Trans. 35 (1992) 482-490.

[11] C. Perrin, W.M. Rainforth, The effect of alumina fibre reinforcement on the wear of an Al-4.3\%Cu alloy, Wear 181-183 (1995) 312-324.

[12] M. Roy, B. Venkataraman, V.V. Bhanuprasad, Y.R. Mahajan, G. Sundararajan, The effect of particulate reinforcement on the sliding wear behaviour of aluminium matrix composites, Metall. Trans. 23A (1992) 2833-2847.

[13] B.N. Pramila Bai, B.S. Ramasesh, M.K. Surappa, Dry sliding wear of A356-Al-SiC composites, Wear 157 (1992) 295-304.

[14] B. Venkataraman, G. Sundararajan, The sliding wear behaviour of Al-SiC particulate composites-I. Macrobehaviour, Acta. mater. 44 (1996) 451-460.

[15] A.T. Alpas, J.D. Embury, Sliding and abrasive wear behaviour of an aluminium (2014) - SiC particle reinforced composite, Scr. Metall. 24 (1990) 931-935.

[16] A. Wang, H.J. Rack, Transition wear behaviour of SiC-particulate and SiC-whiskerreinforced 7091 Al metal matrix composites, Mater. Sci. Eng. A147 (1991) 211-224.

[17] Y. Wang, W.M. Rainforth, H. Jones, M. Lieblich, Sliding wear behaviour of novel AA2124 aluminium alloy/Ni ${ }_{3} \mathrm{Al}$ composites, Mater. Sci. Technol. 396-402 (2002) 1473-1478. 
[18] Y. Wang, W.M. Rainforth, H. Jones, M. Lieblich, Dry wear behaviour and its relation to microstructure of novel 6092 aluminium alloy- $\mathrm{Ni}_{3} \mathrm{Al}$ powder metallurgy composite, Wear 251 (2001) 1421-1432.

[19] H. Omura, T. Miyoshi, Y. Takahashi, J.G. Conley, M. Yodogawa, Dispersion of NiAl intermetallic compound and $\mathrm{Si}_{3} \mathrm{~N}_{4}$ in die castings for increased wear resistance, in: Y. W. Kim and W. M. Griffith, Dispersion strengthened aluminium alloys, The Minerals, Metals and Materials Society, Warrendale, Pennsylvania, pp, 421-435.

[20] C.E. da Costa, W.C. Zapata, F. Velasco, J.M. Ruiz-Prieto, J.M. Torralba, Wear behaviour of aluminium reinforced with nickel aluminide MMCs, J. Mater. Proc. Tech. 92-93 (1999) 66-70.

[21] C. Diaz, J.L. Gonzalez-Carrasco, G. Caruana, M. Lieblich, $\mathrm{Ni}_{3} \mathrm{Al}$ intermetallic particles as wear-resistant reinforcement for Al-base composites processed by powder metallurgy, Metall. Trans. 27A (1996) 3259-3266.

[22] B. Torres, M. Lieblich, J. Ibanez, A. Garcia-Escorial, Mechanical properties of some PM aluminide and silicide reinforced 2124 aluminium matrix composites, Scr. Metall. 47 (2002) 45-49.

[23] Z. Hashin, B.W. Rosen, The elastic modulus of fibre reinforced materials, J.Appl.Mech (Trans. ASME) (1964) 223.

[24] J.K. Lancaster, Wear 10 (1967) 103.

[25] Y. Sakai, T. Yamada, T. Suzuki, T. Sato, H. Itoh, T. Ichinokawa, Contrast mechanisms in scanning ion microscope imaging for metals, Appl. Phys. Lett. 73 (1998) 611-613.

[26] T. Suzuki, N. Endo, M. Shibata, S. Kamasaki, T. Ichinokawa, Contrast differences between scanning ion and scanning electron microscope images, J. Vac. Sci. Technol. A 22 (2004) 49-52. 
[27] M.J. Ghazali, W.M. Rainforth, H. Jones, Dry sliding wear behaviour of some wrought, rapidly solidified powder metallurgy aluminium alloys, Submitted to, Wear (2005)

[28] I.M. Hutchings, Tribology, Butterworth-Heinemann, Cambridge, 1992,

[29] A.P. Sannino, H.J. Rack, Dry sliding wear of discontinuously reinforced aluminium composites: review and discussion, Wear 189 (1995) 1-19. 


\begin{tabular}{lllllllll}
\hline Weight $\%$ & $\mathrm{Si}$ & $\mathrm{Fe}$ & $\mathrm{Cu}$ & $\mathrm{Mn}$ & $\mathrm{Mg}$ & $\mathrm{Cr}$ & Others & $\mathrm{Al}$ \\
\hline 2124 & 0.03 & 0.06 & 4.24 & 0.85 & 1.40 & $<0.01$ & $<0.01$ & Balance \\
5056 & 0.02 & 0.02 & 0.03 & 0.13 & 5.01 & 0.09 & $<0.05$ & Balance \\
\hline \multicolumn{7}{l}{ Table 1. Specified alloy compositions (wt.\%) for 2124 and 5056; from Alpoco,UK. }
\end{tabular}

\begin{tabular}{ccc}
\hline Material & $\begin{array}{c}\text { Density } \\
\left(\mathrm{g} / \mathrm{cm}^{3}\right)\end{array}$ & $\begin{array}{c}\text { Elastic Modulus } \\
(\mathrm{GPa})\end{array}$ \\
\hline $\mathrm{SiC}$ & 3.20 & 450 \\
$\mathrm{Ni}_{3} \mathrm{Al}$ & 7.40 & 180 \\
$\mathrm{Cr}_{3} \mathrm{Si}$ & 6.54 & 351 \\
$\mathrm{MoSi}_{2}$ & 6.20 & 440 \\
$\mathrm{Al}$ & 2.70 & 75 \\
\hline
\end{tabular}

Table 2. Properties of reinforcement phases; from INSAMET, Spain.

\begin{tabular}{ccc}
\hline & $\begin{array}{c}\text { Initial Hertzian } \\
\text { Contact Stress }(\mathrm{MPa})\end{array}$ & $\begin{array}{c}\text { Uniaxial Yield } \\
\text { strength, } \sigma_{y}, \text { from } \\
3.3 \mathrm{H}_{\mathrm{v}}(\mathrm{MPa})\end{array}$ \\
\hline 2124 & 683 & 394 \\
5056 & 673 & 316 \\
$2124+\mathrm{Cr}_{3} \mathrm{Si}$ & 845 & 422 \\
$5056+\mathrm{Cr}_{3} \mathrm{Si}$ & 840 & 373 \\
$2124+\mathrm{MoSi}_{2}$ & 869 & 419 \\
$5056+\mathrm{MoSi}_{2}$ & 863 & 360 \\
$2124+\mathrm{SiC}$ & 891 & 603 \\
$5056+\mathrm{Ni}_{3} \mathrm{Al}$ & 746 & 379 \\
\hline
\end{tabular}

Table 3. Initial maximum Hertzian contact stresses (MPa) for point contact at $630 \mathrm{~N}$ normal load.

\begin{tabular}{cccc}
\hline & $\begin{array}{c}\text { Total Sliding } \\
\text { Distance }(\mathrm{km})\end{array}$ & $\begin{array}{c}\text { Average Friction } \\
\text { Coefficient, } \mu\end{array}$ & $\begin{array}{c}\text { Dimensional Wear } \\
\text { Coefficient, } K^{\prime}\left(\mathrm{mm}^{3} / \mathrm{Nm}\right)\end{array}$ \\
\hline $2124 \mathrm{Alloy}$ & 469 & 0.02 & $5.09 \times 10^{-10}$ \\
$5056 \mathrm{Alloy}$ & 617 & 0.01 & $1.09 \times 10^{-9}$ \\
$2124+\mathrm{Cr}_{3} \mathrm{Si}$ & 421 & 0.02 & $1.42 \times 10^{-10}$ \\
$5056+\mathrm{Cr}_{3} \mathrm{Si}$ & 511 & 0.08 & $1.32 \times 10^{-10}$ \\
$2124+\mathrm{MoSi}_{2}$ & 374 & 0.11 & $9.86 \times 10^{-11}$ \\
$5056+\mathrm{MoSi}_{2}$ & 467 & 0.06 & $8.29 \times 10^{-11}$ \\
$2124+\mathrm{SiC}$ & 548 & 0.03 & $1.96 \times 10^{-10}$ \\
$5056+\mathrm{Ni}_{3} \mathrm{Al}$ & 543 & 0.02 & $1.94 \times 10^{-10}$ \\
\hline
\end{tabular}

Table 4. Wear test data for lubricated sliding at $630 \mathrm{~N}$ load, $0.93 \mathrm{~ms}^{-1}$. 


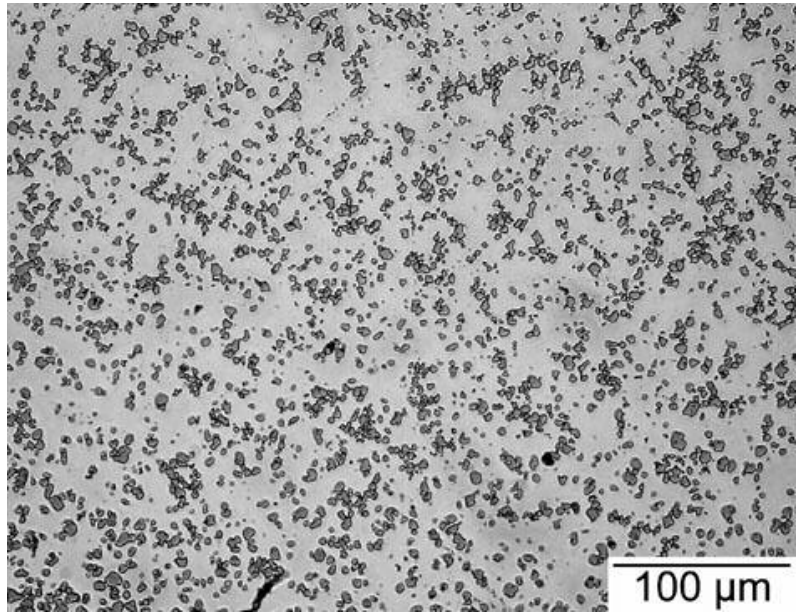

Figure 1. Optical micrograph of $5056+$ $15 \mathrm{vol} \% \mathrm{MoSi}_{2}$ showing an even particle distribution after extrusion.

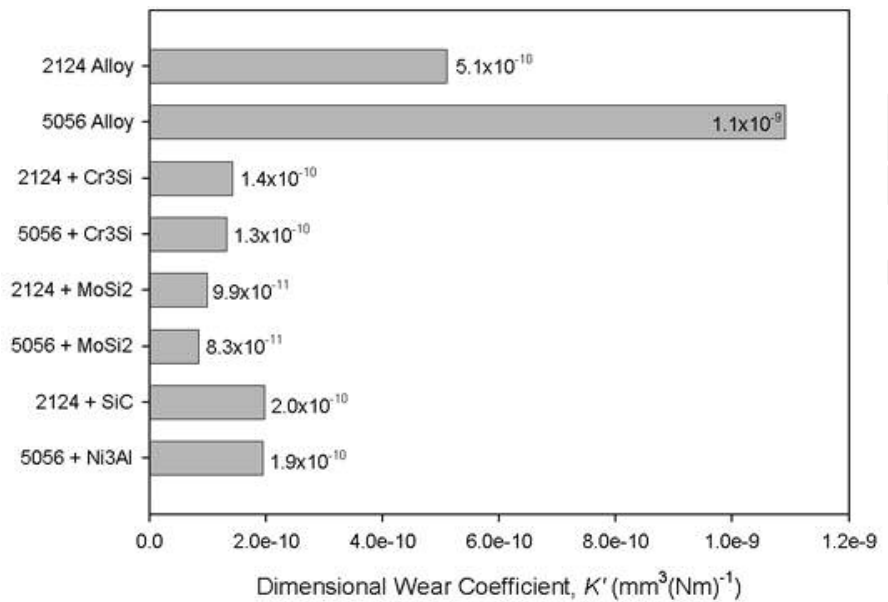

Figure 3. Dimensional Wear Coefficient, $K^{\prime}$ for lubricated sliding wear of 2124 and 5056 alloys and composites, at $630 \mathrm{~N}$ normal load, based upon volume loss measurements calculated from wear scar geometry.

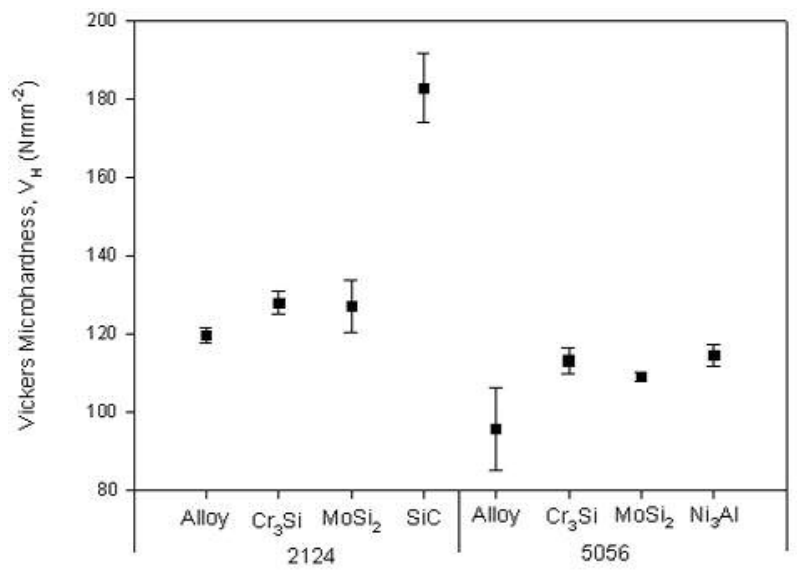

Figure 2. Vickers microhardness (200g, 15s) for 2124 and 5056 alloys and composites.

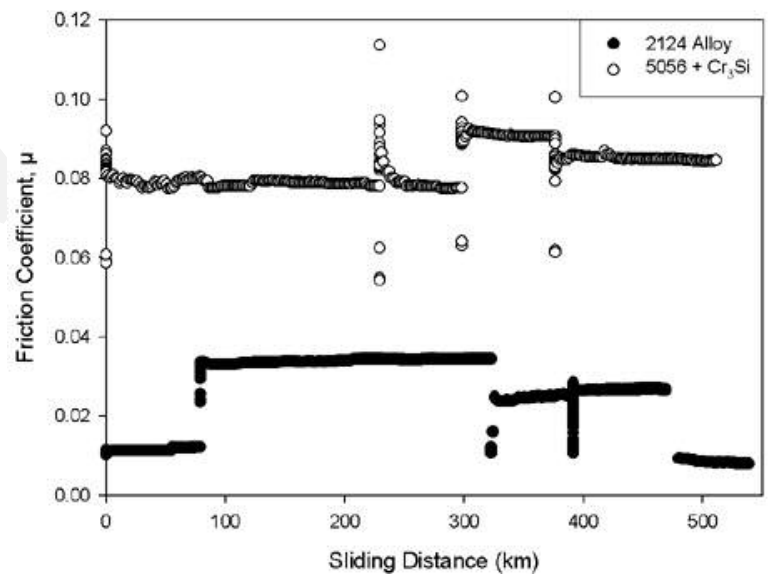

Figure 4. Friction Coefficient $(\mu)$ values for lubricated wear tests of 2124 alloy and 5056 $+\mathrm{Cr}_{3} \mathrm{Si}$ at $630 \mathrm{~N}$ load, as a function of sliding distance $(\mathrm{km})$. 


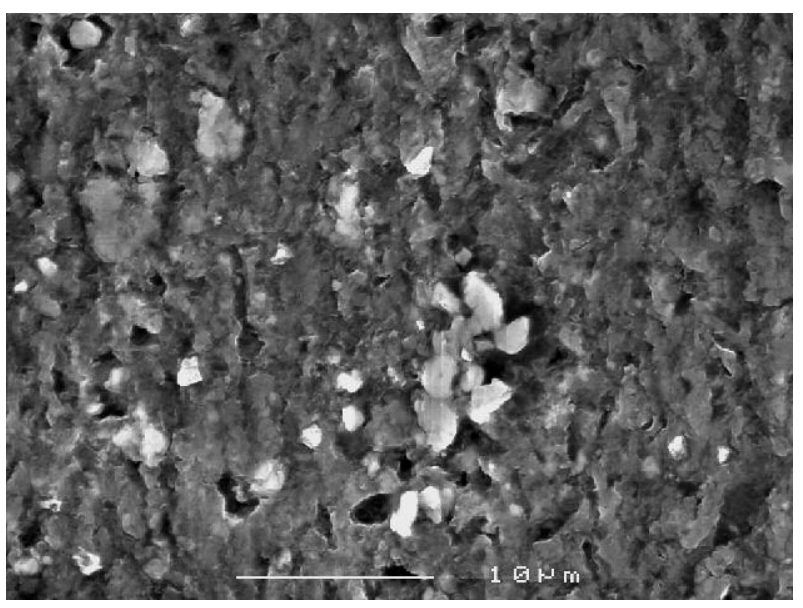

a) 2124 Alloy

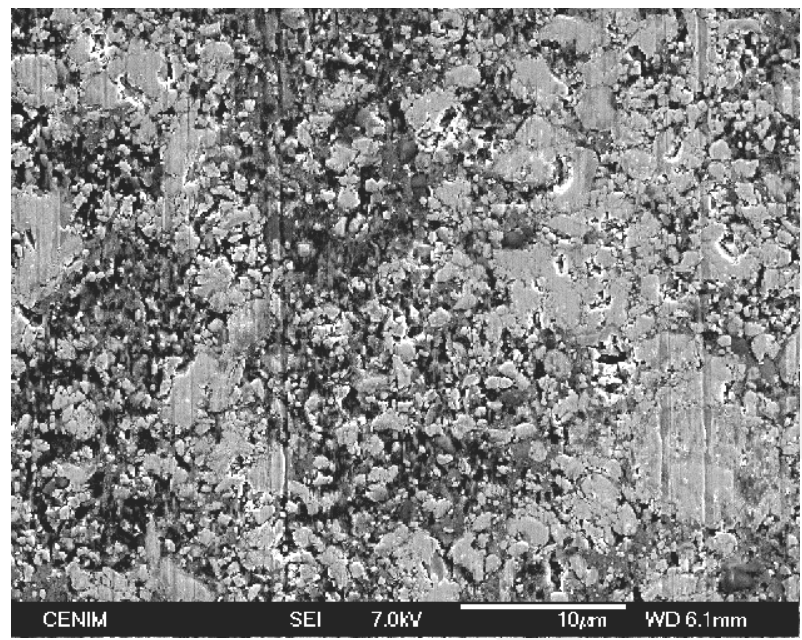

c) $2124+\mathrm{Cr}_{3} \mathrm{Si}$

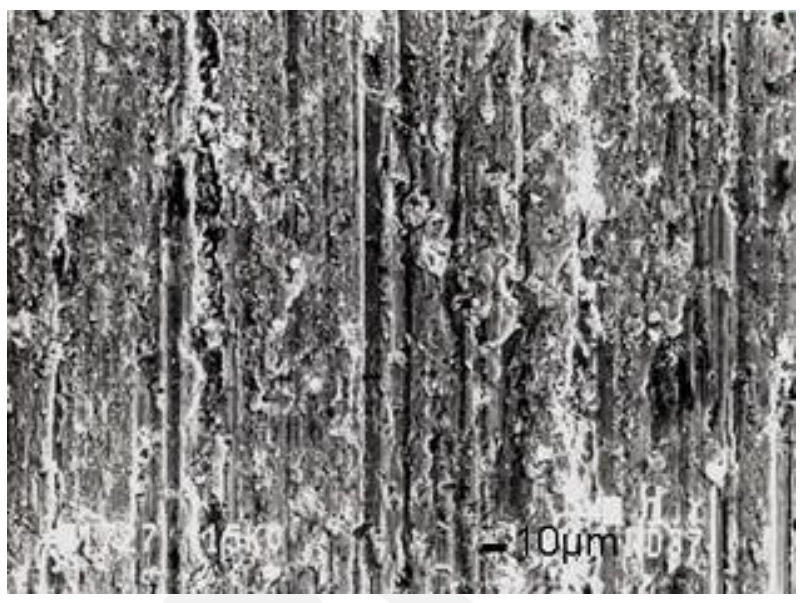

b) $2124+\mathrm{SiC}$

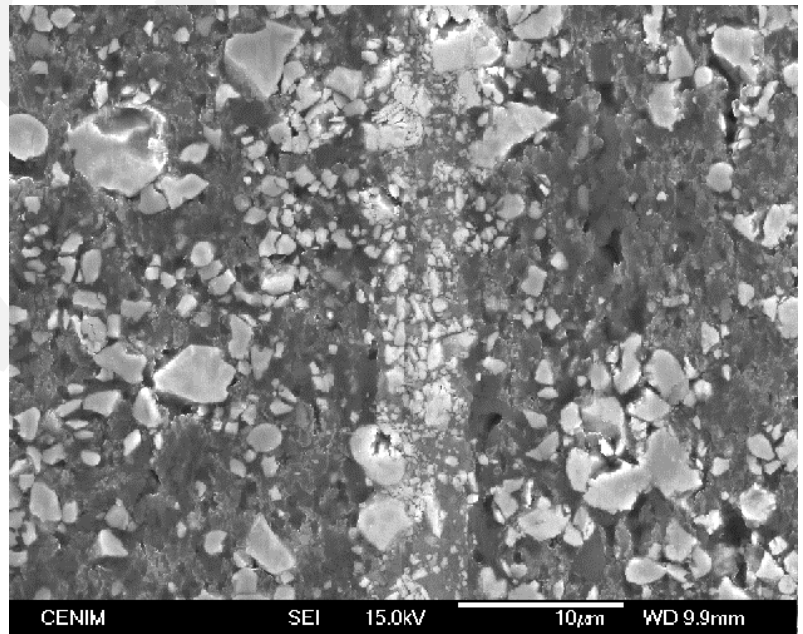

d) $2124+\mathrm{MoSi}_{2}$

Figure 5. Secondary electron SEM micrographs of 2124 alloy and composites after lubricated wear at $630 \mathrm{~N}$ normal load for a) $496 \mathrm{~km}$, b) $548 \mathrm{~km}$ c) $421 \mathrm{~km}$ and d) $374 \mathrm{~km}$; sliding direction is in the vertical direction. 


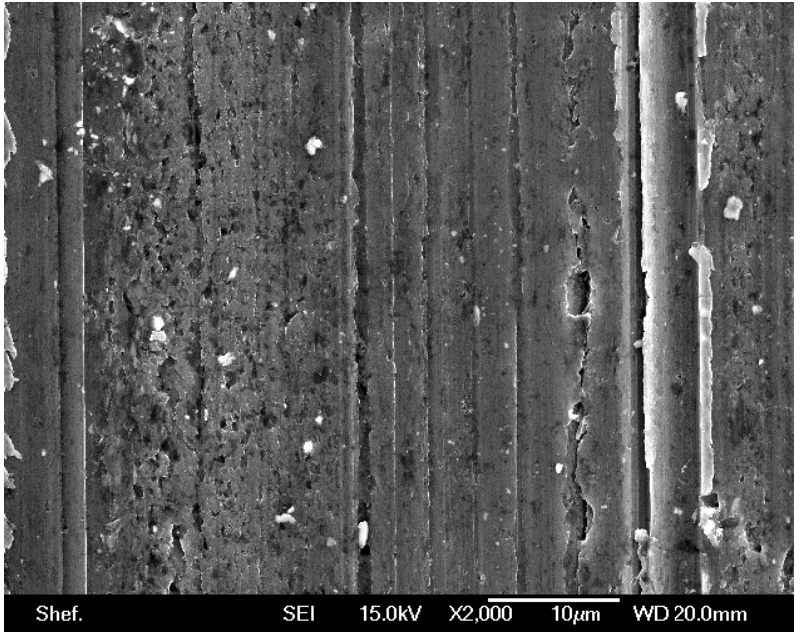

a) 5056 Alloy

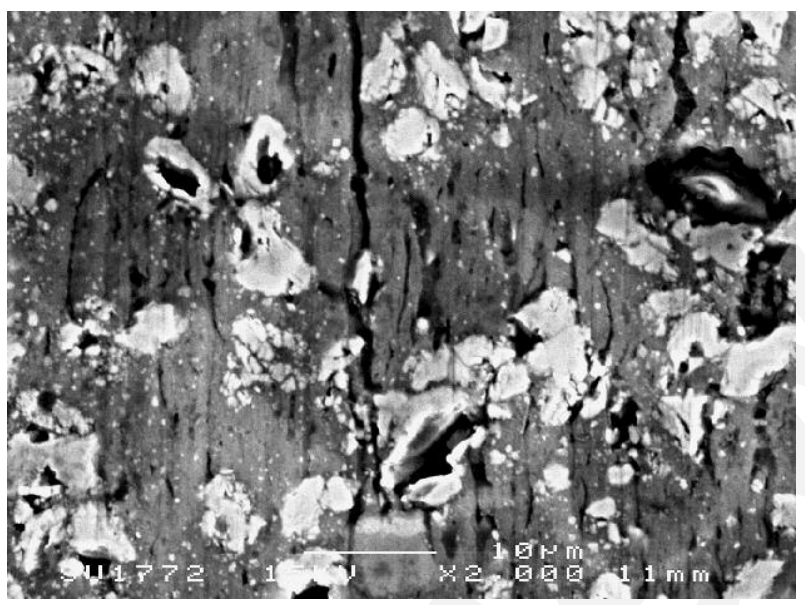

c) $5056+\mathrm{Cr}_{3} \mathrm{Si}$

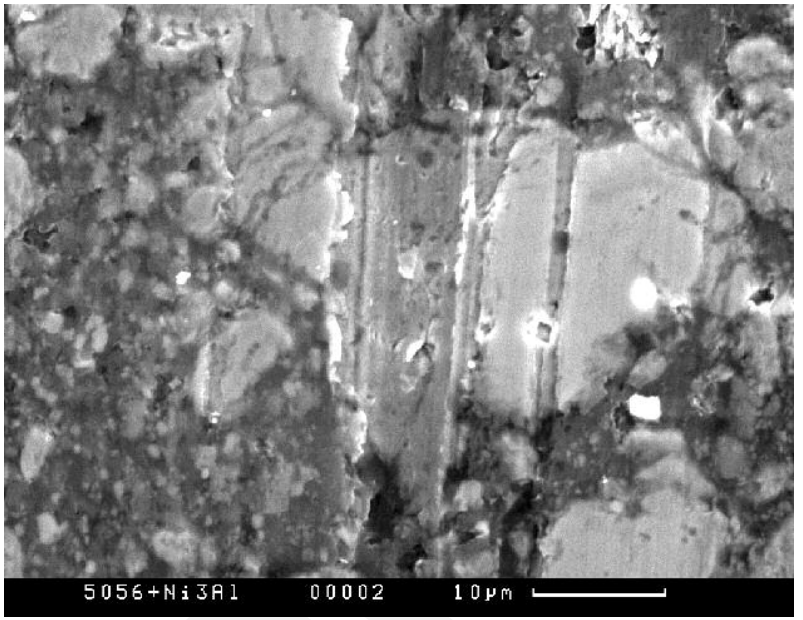

b) $5056+\mathrm{Ni}_{3} \mathrm{Al}$

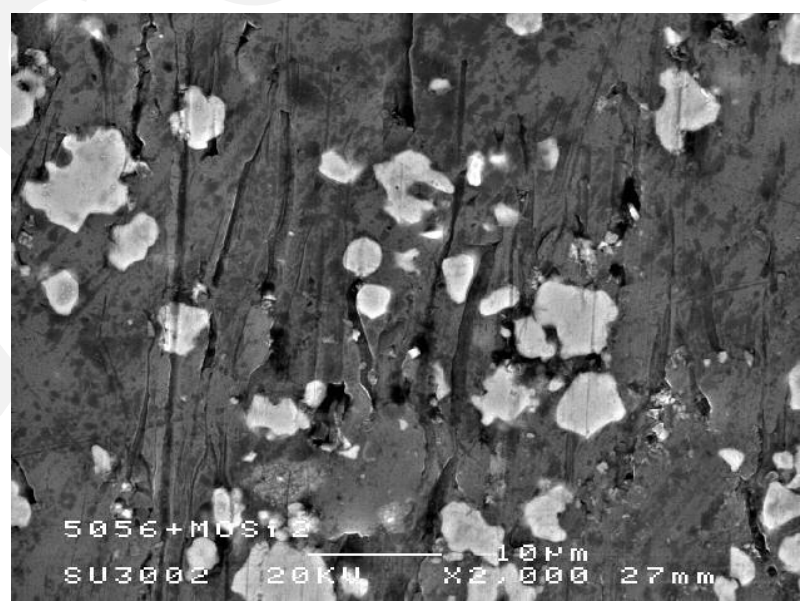

d) $5056+\mathrm{MoSi}_{2}$

Figure 6. Secondary electron SEM micrographs of 5056 alloy and composites after lubricated wear at $630 \mathrm{~N}$ normal load for a) $617 \mathrm{~km}$, b) $543 \mathrm{~km}$, c) $511 \mathrm{~km}$, and d) $467 \mathrm{~km}$; sliding direction is in the vertical direction. 


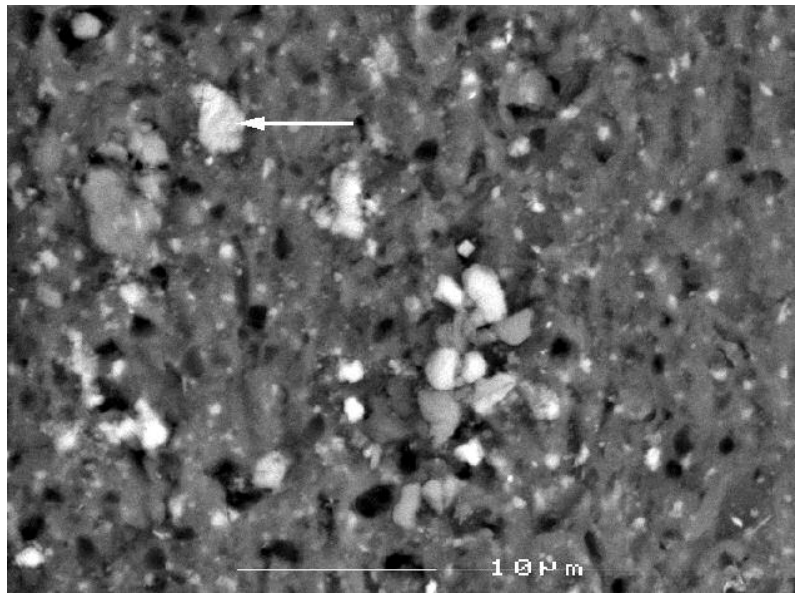

a) 2124 alloy

cps

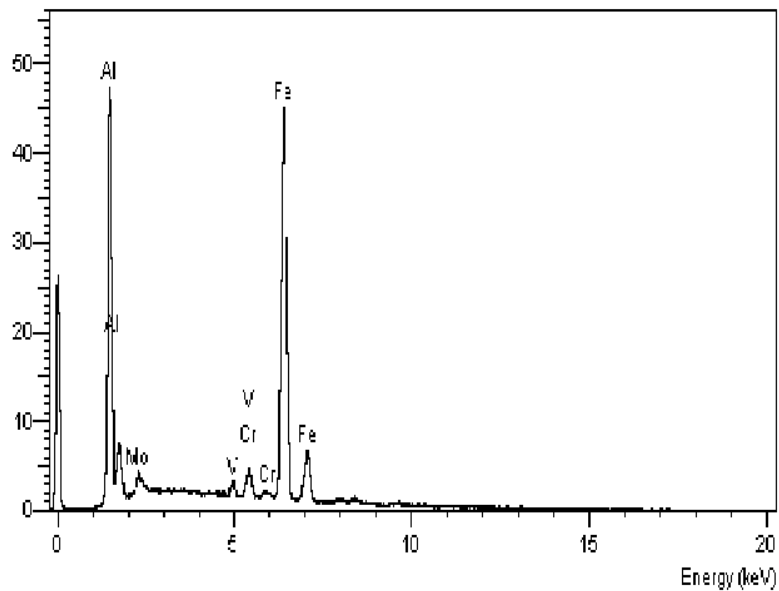

c) EDX spectra of arrowed particle in a).

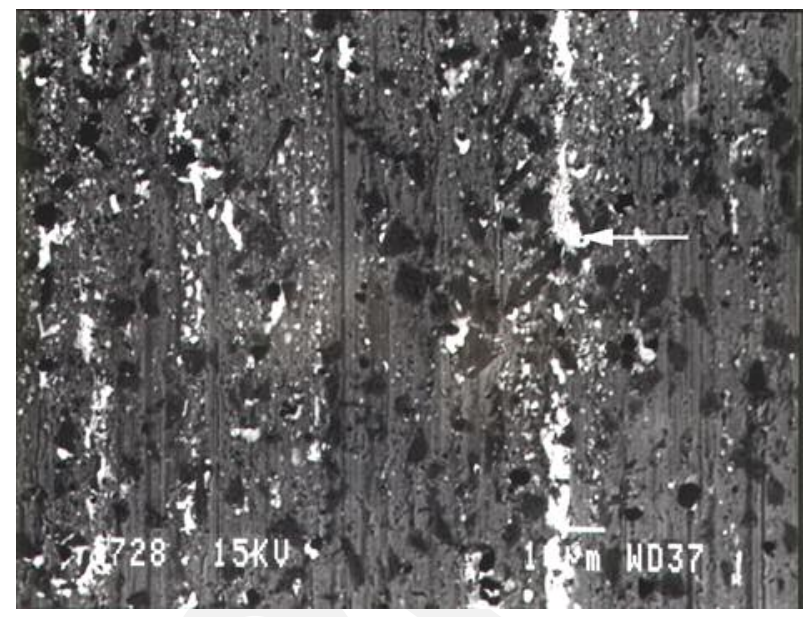

b) $2124+\mathrm{SiC}$

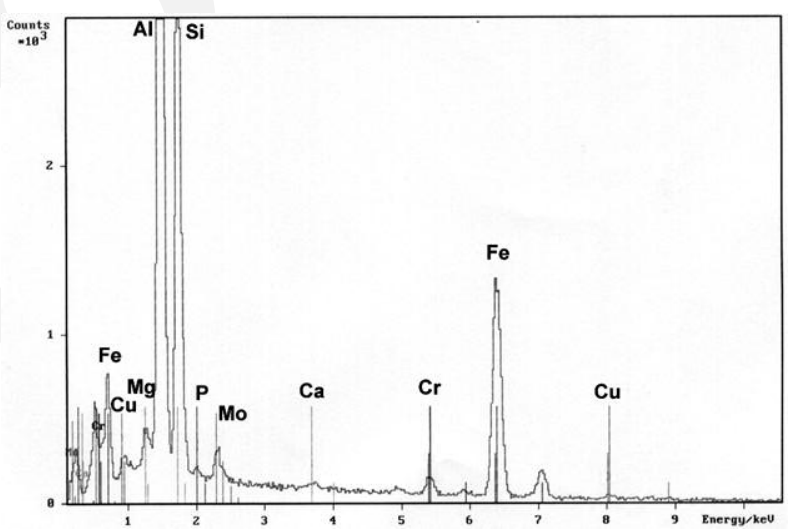

d) EDX spectra of arrowed particle in b).

Figure 7. Backscattered SEM images corresponding to Figures 5a) and b), showing evidence of Fe transfer from counterface. Arrows indicate sampling point of EDX spectra c) and d) for 2124 and $2124+\mathrm{SiC}$, respectively. 

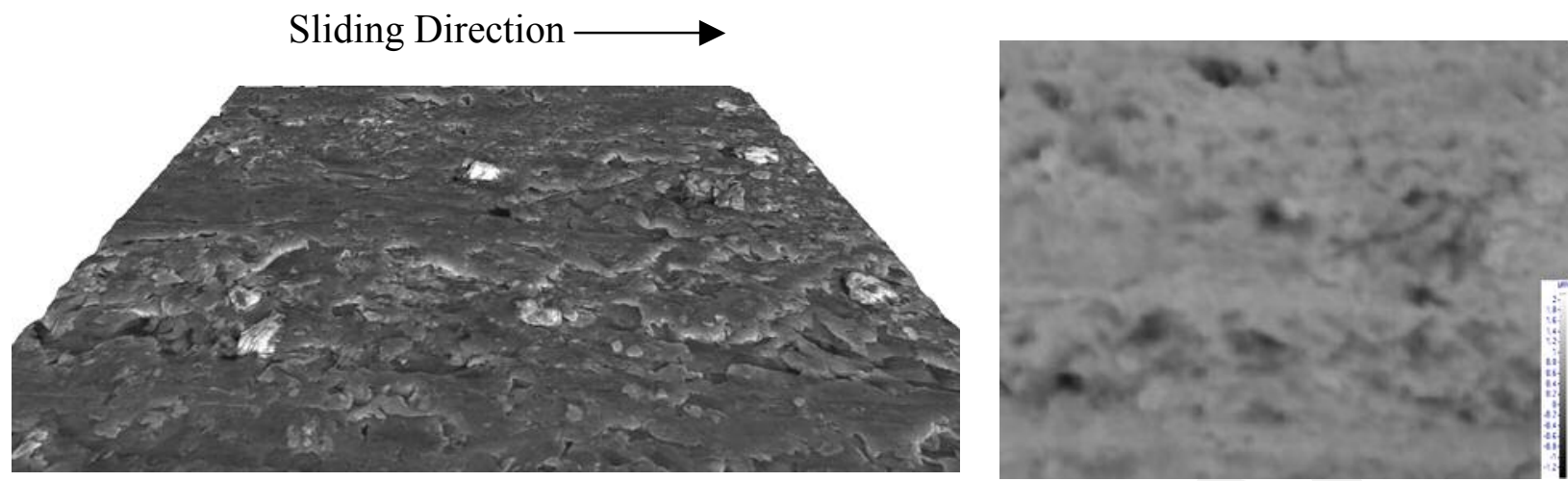

Figure 8 . Tilted tomographic surface reconstruction of 5056 Alloy at $\times 1000$ magnification, left, and corresponding texture depth image, right.
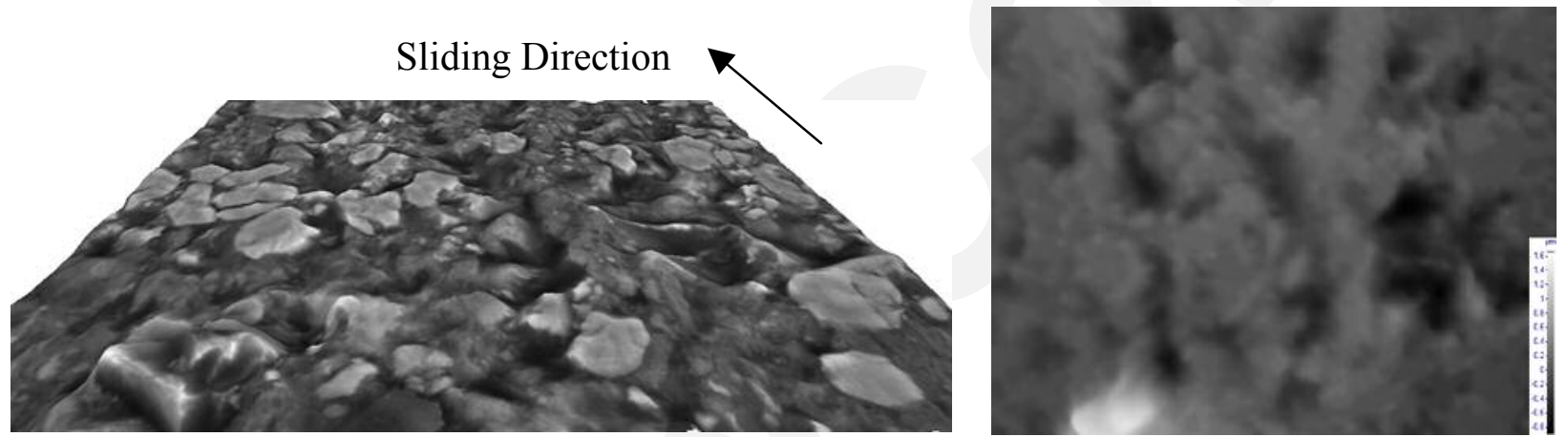

Figure 9. Tilted tomographic surface reconstruction of $5056+\mathrm{MoSi}_{2}$ at $\times 3000$ magnification, left, and corresponding texture depth image, right.
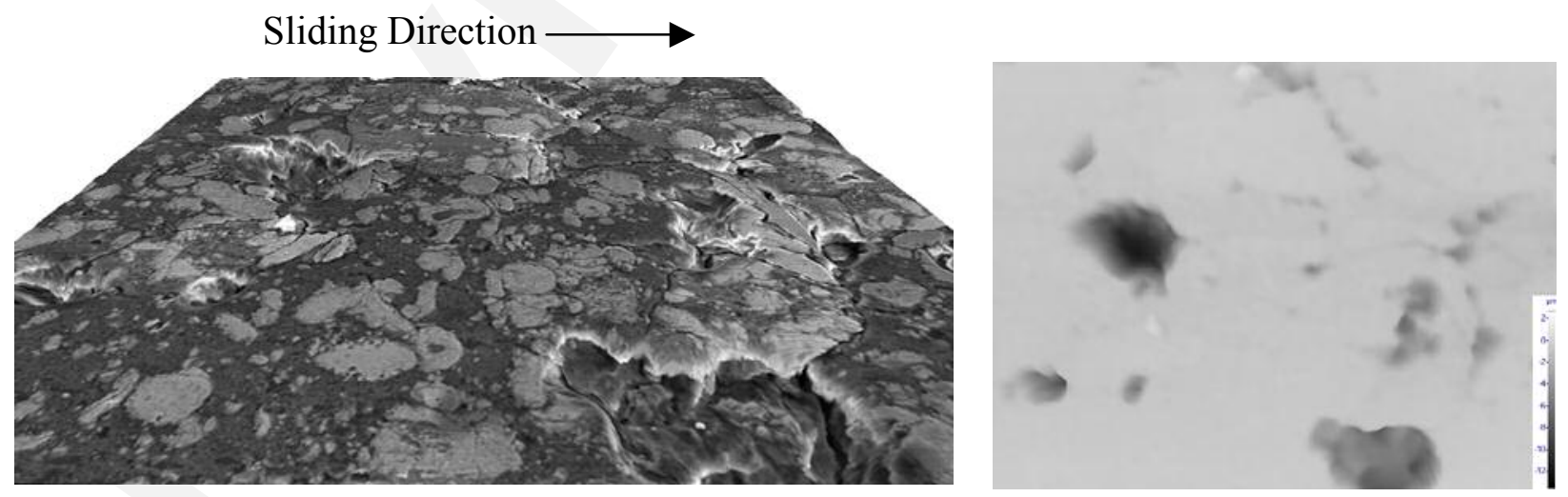

Figure 10. Tilted tomographic surface reconstruction of $5056+\mathrm{Ni}_{3} \mathrm{Al}$ at $\times 500$ magnification, left, and corresponding texture depth image, right. 

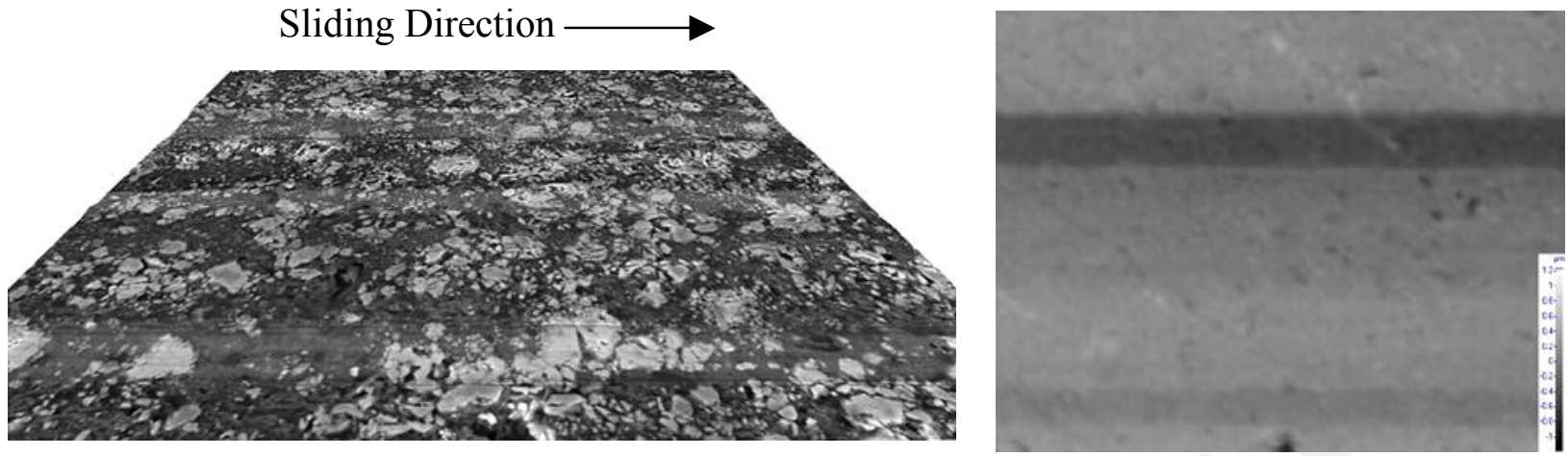

Figure 11. Tilted tomographic surface reconstruction of $2124+\mathrm{MoSi}_{2}$ at $\times 1000$ magnification, left, and corresponding texture depth image, right.
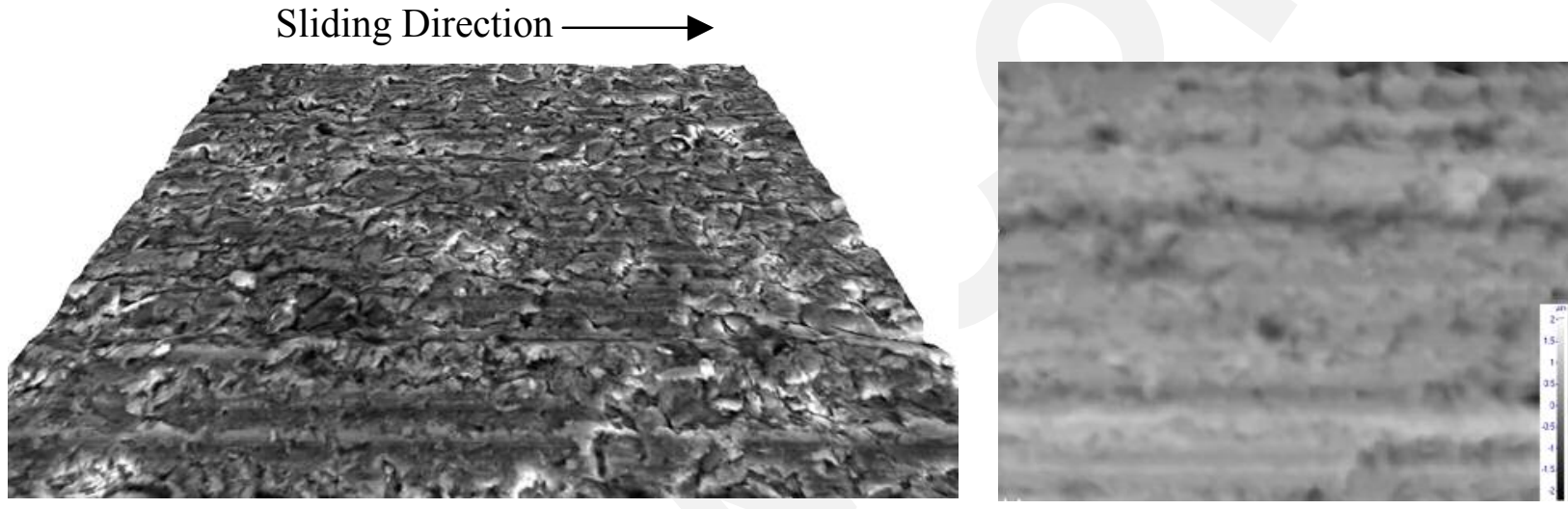

Figure 12. Tilted tomographic surface reconstruction of $2124+\mathrm{SiC}$ at $\times 1000$ magnification, left, and corresponding texture depth image, right.
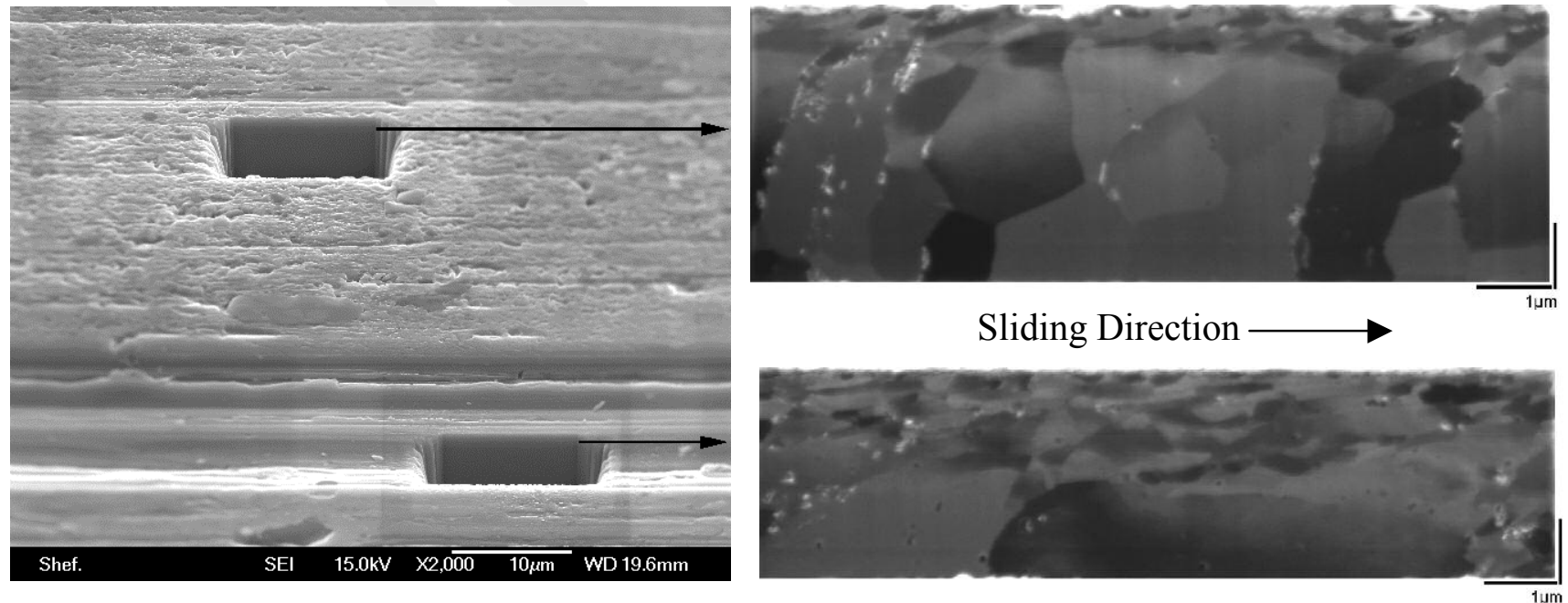

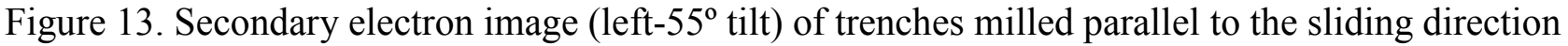
in 5056 alloy after lubricated sliding at $630 \mathrm{~N}$ for $306 \mathrm{~km}$. Secondary ion images at $63^{\circ}$ tilt of the subsurface faces are shown to the right. 

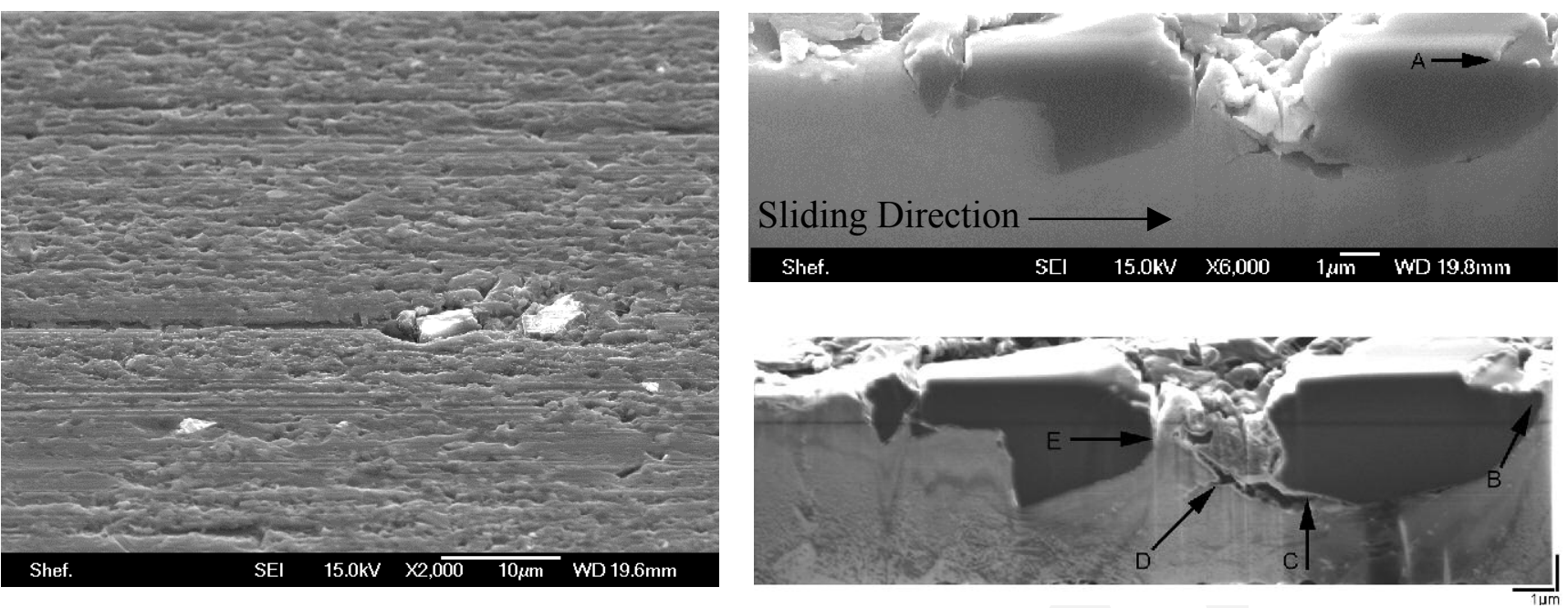

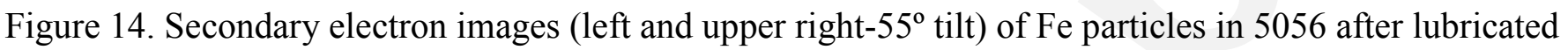
sliding for $306 \mathrm{~km}$. The secondary ion image of the same area is shown lower right at $63^{\circ}$ tilt, with letters A-E corresponding to features described in the text.
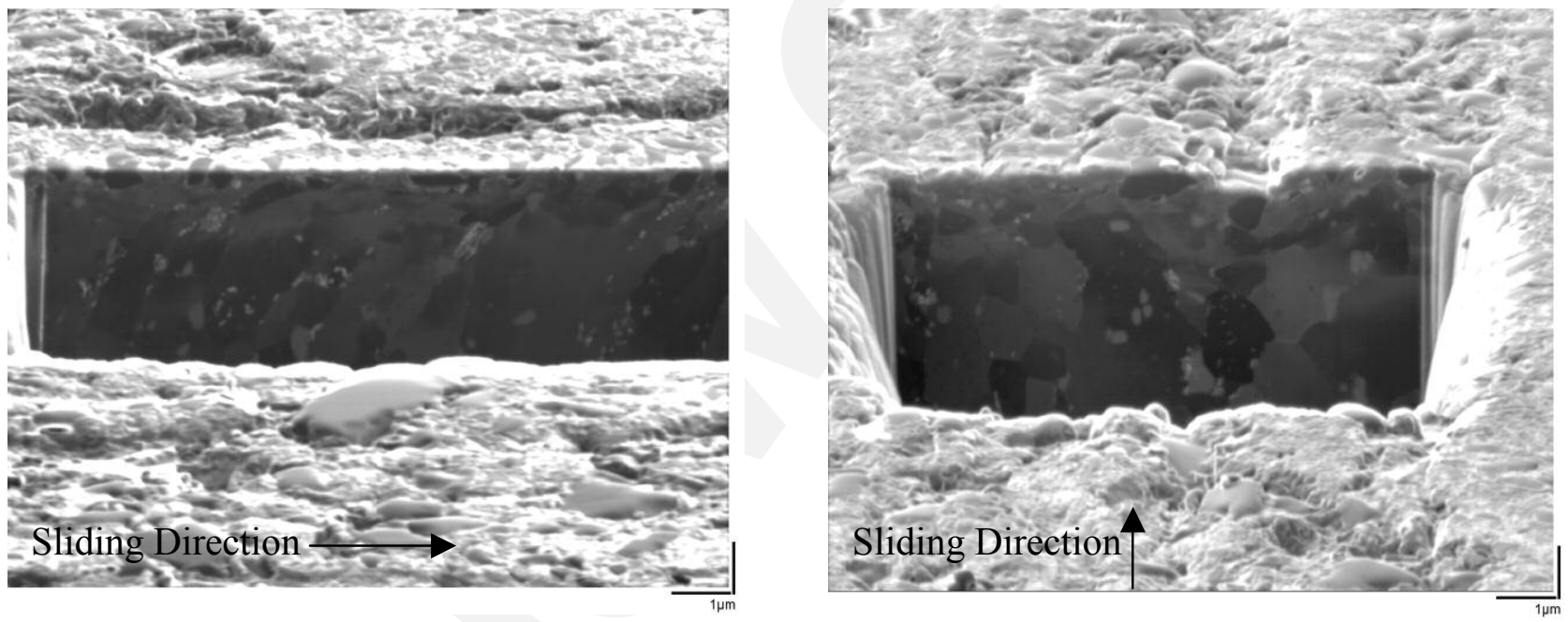

Figure 15. Secondary ion images $\left(63^{\circ}\right.$ tilt), showing channelling contrast of the subsurface microstructure in 2124 alloy, after lubricated sliding for $469 \mathrm{~km}$.
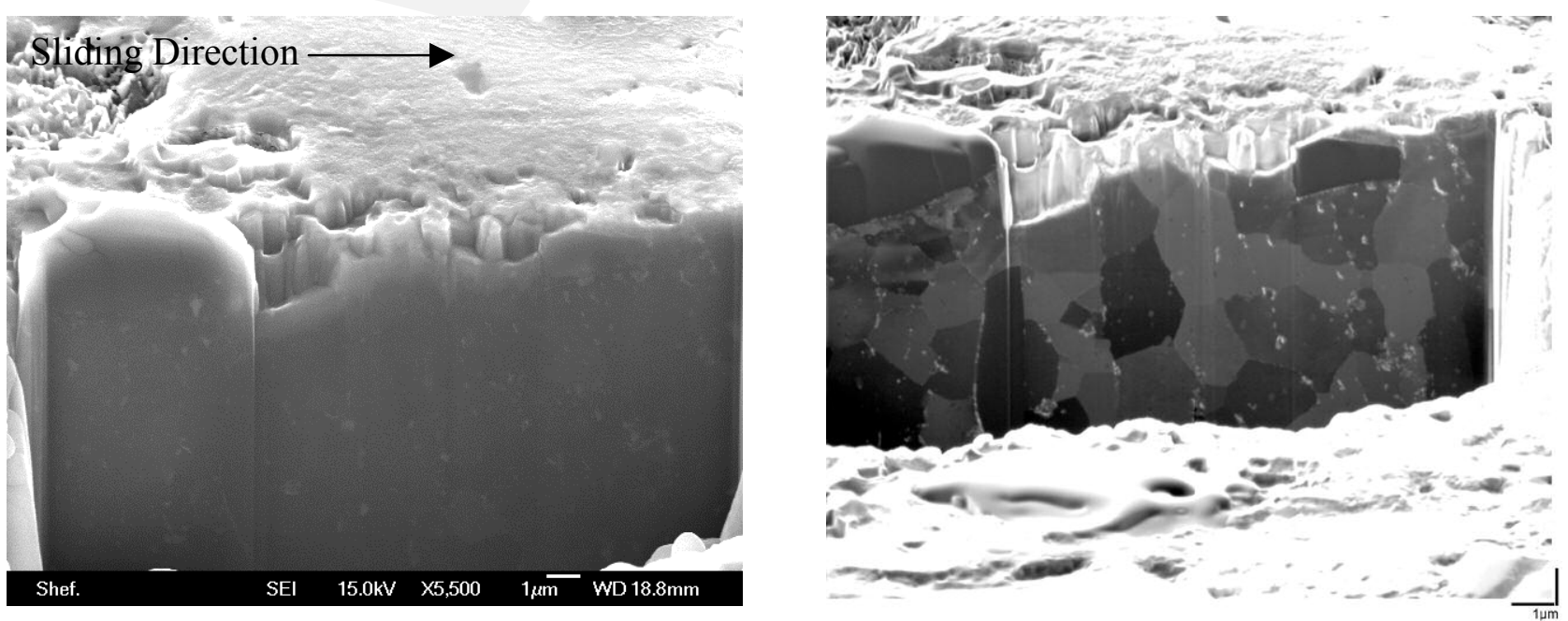

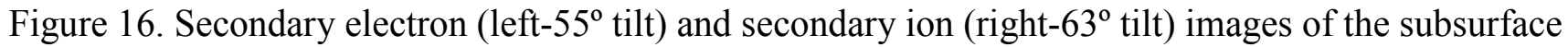
region of $2124+\mathrm{SiC}$, after lubricated wear for $548 \mathrm{~km}$. 

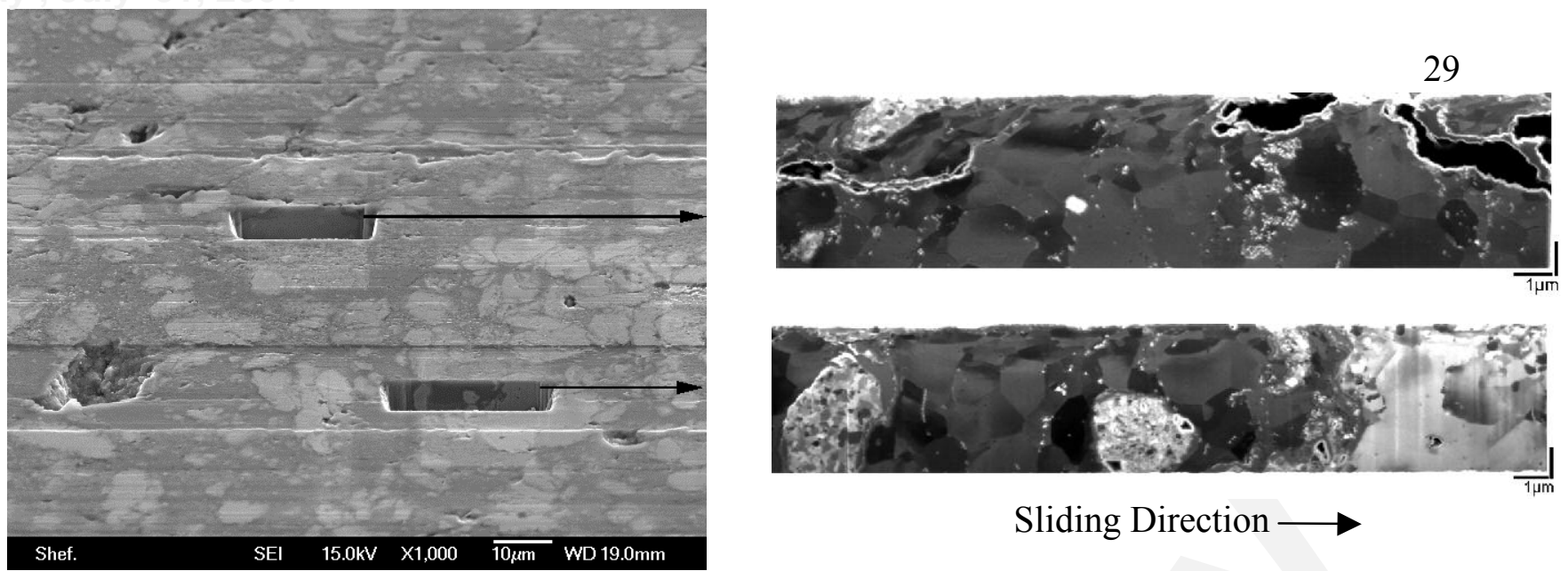

Sliding Direction $\longrightarrow$

Figure 17. Secondary electron image (left $-55^{\circ}$ ) of a trenches in the worn surface of $5056+\mathrm{Ni}_{3} \mathrm{Al}$.

Secondary ion images of the sub-surface areas are shown to the right $\left(67^{\circ}\right.$ tilt $)$.

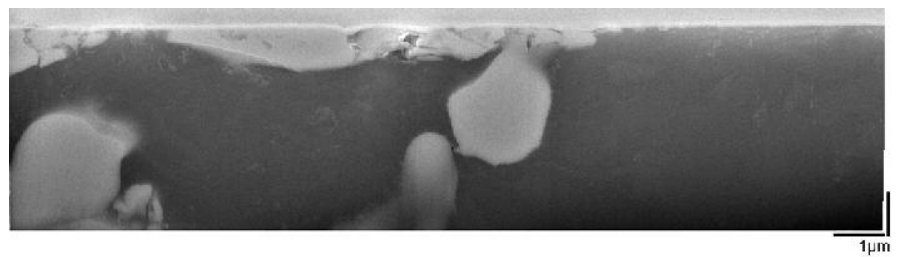

a) $5056+\mathrm{MoSi}_{2}-\mathrm{SEM}$

Sliding Direction $\longrightarrow$

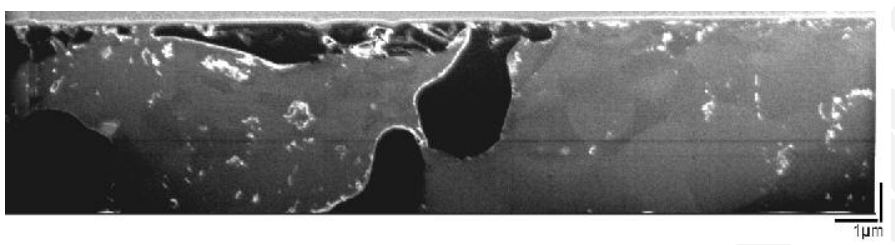

c) $5056+\mathrm{MoSi}_{2}$-FIB

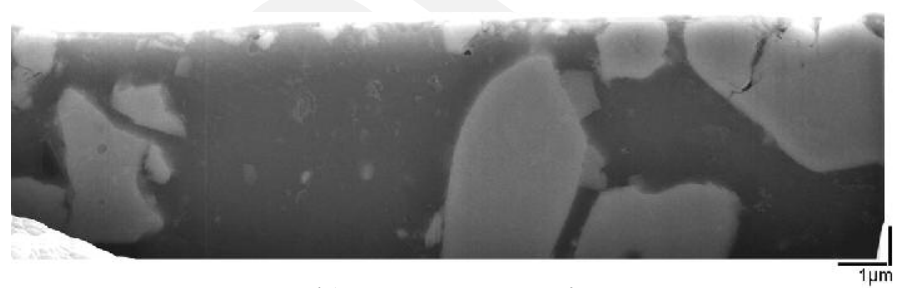

b) $2124+\mathrm{Cr}_{3} \mathrm{Si}-\mathrm{SEM}$

Sliding Direction

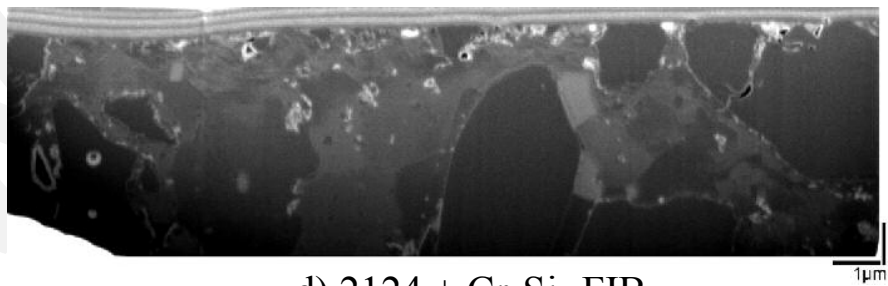

d) $2124+\mathrm{Cr}_{3} \mathrm{Si}-\mathrm{FIB}$

Figure 18. Secondary electron images ( $55^{\circ}$ tilt $)$ of trenches within the wear tracks of a) $5056+\mathrm{MoSi}_{2}$ and b) $2124+\mathrm{Cr}_{3} \mathrm{Si}$, after lubricated sliding for $467 \mathrm{~km}$ and $421 \mathrm{~km}$ respectively. Secondary ion images c) and d), below, are of the same areas $\left(63^{\circ}\right.$ tilt $)$. Note the platinum deposit at the top of these trenches, to protect the worn surface.
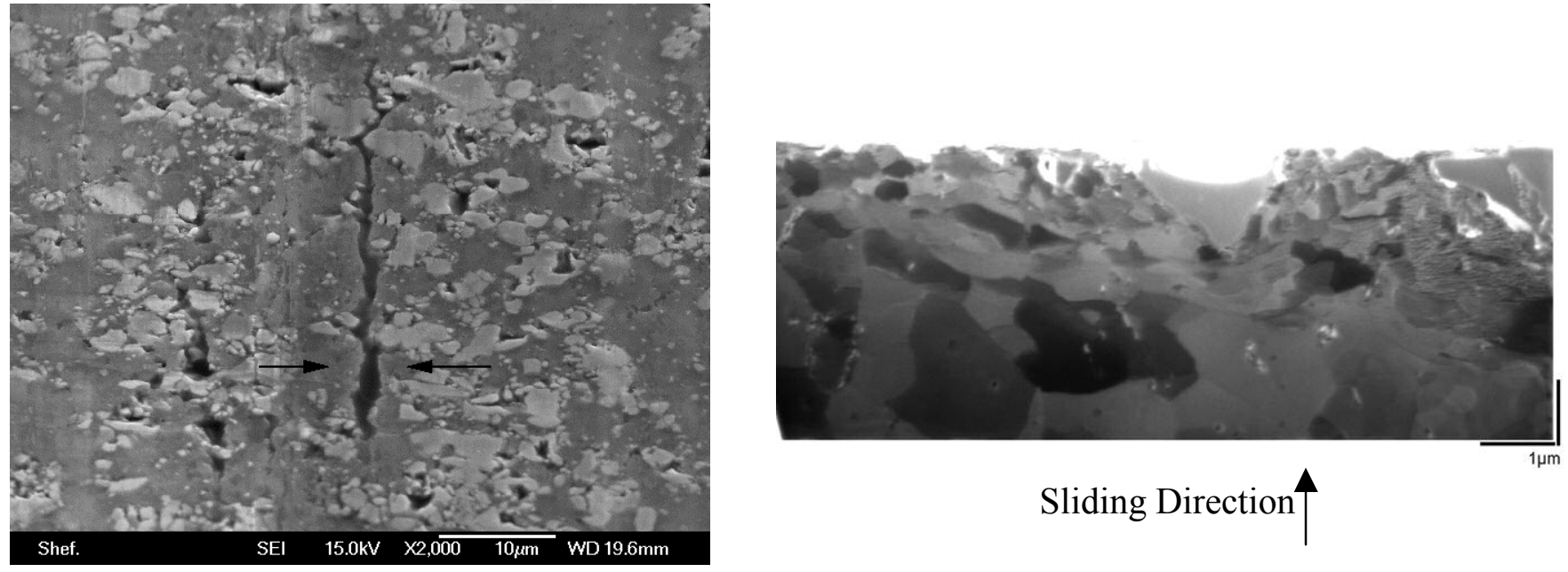

Figure 19. Secondary electron image (left $-55^{\circ}$ tilt) of a non-linear wear track in $5056+\mathrm{MoSi}_{2}$ and secondary ion image (right- $63^{\circ}$ tilt) of a trench milled between arrows; lubricated sliding for $467 \mathrm{~km}$. 